\title{
Logical Squares for Classical Logic Sentences
}

\author{
Urszula Wybraniec-Skardowska
}

\begin{abstract}
In this paper, with reference to relationships of the traditional square of opposition, we establish all the relations of the square of opposition between complex sentences built from the 16 binary and four unary propositional connectives of the classical propositional calculus (CPC). We illustrate them by means of many squares of opposition and, corresponding to them-octagons, hexagons or other geometrical objects.
\end{abstract}

Mathematics Subject Classification. Primary 03B05, 03B65; Secondary $03 \mathrm{~B} 80$.

Keywords. Square of opposition, classical propositional connectives, truth-value table, tautology of classical logic, octagon of opposition, hexagon of opposition, octahedron of opposition.

\section{Introduction: Basic Definitions}

For any sentences $\alpha, \beta, \varphi, \psi$ of $\mathrm{CPC}$ we assume the following definitions:

$\alpha, \beta$ are contrary iff $\alpha / \beta$ is a tautology of CPC, where the stroke/is the Sheffer's connective;

$\varphi, \psi$ are subcontrary iff $\varphi \vee \psi$ is a tautology of CPC, where $\vee$ is the disjunction connective;

$\alpha$ entails $\varphi$ iff $\alpha \rightarrow \varphi$ is a tautology of CPC, where $\rightarrow$ is the implication connective;

$\alpha$ and $\psi$ are contradictory iff $(\alpha \wedge \psi) \vee(\sim \alpha \wedge \sim \psi)$ is a counter-tautology of CPC, i.e. $\alpha$ and $\psi$ never agree in truth-values.

We will illustrate the above relationships between sentences $\alpha, \beta, \varphi, \psi$ in a square of opposition graphically in a non-standard way ${ }^{1}$ by means of Fig. 1 , where the dotted lines indicate contradictory sentences and the downward arrows the implication.

\footnotetext{
${ }^{1}$ First logicians who tried to organize or 'structure' the connectives of CPC in a systematic way were $[3,5,7,11]$. A description of the paper by [5] is given by Beziau [2]: http://cahiers. kingston.ac.uk/synopses/syn10.7.html.
} 


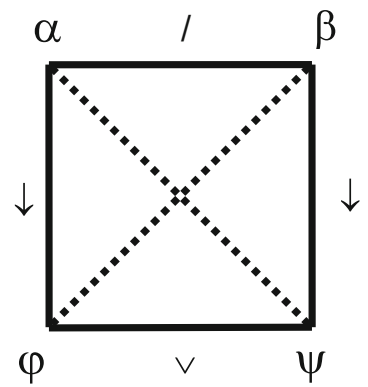

FiguRE 1. Scheme of square of opposition

\section{Connectives: both ... and...; ... unless...; not... because...; neither ...nor... ${ }^{2}$}

Among the 16 binary classical sentence-forming connectives there are only four for which sentences that are built by means of them are true only in one case (see Table 1). They are the following:

both ... and. . , . . . unless. . , not. . because. . , neither ... nor. . . (binegation $\downarrow)$.

We define them by means of variables $p, q$ and the classical connectives: the conjunction $\wedge$ (or implication $\rightarrow$ ) and negation $\sim$ as follows:

both $\mathrm{p}$ and $\mathrm{q}=\mathrm{df} \mathrm{p} \wedge \mathrm{q}$;

$\mathrm{p}$ unless $\mathrm{q}={ }_{\mathrm{df}} \sim(\mathrm{p} \rightarrow \mathrm{q}) \equiv \mathrm{p} \wedge \sim \mathrm{q}$;

not $\mathrm{p}$ because $\mathrm{q}($ or not $\mathrm{p}$ though $\mathrm{q})=_{\mathrm{df}} \sim(\mathrm{q} \rightarrow \mathrm{p}) \equiv \sim \mathrm{p} \wedge \mathrm{q}$;

neither $\mathrm{p}$ nor $\mathrm{q}(\mathrm{p} \downarrow \mathrm{q})=_{\mathrm{df}} \sim \mathrm{p} \wedge \sim \mathrm{q}$.

The third connective is also called the dual implication: $\mathrm{d}(\mathrm{p} \rightarrow \mathrm{q}){ }_{\mathrm{df}}$ $\sim(\mathrm{q} \rightarrow \mathrm{p})$ (see $[16,17])$ and the last one is known as binegation $\downarrow$.

The truth-value table for these connectives is the following:

TABLE 1. The truth-value table for conjunctive sentences

\begin{tabular}{llllll}
\hline $\mathrm{p}$ & $\mathrm{q}$ & $\mathrm{p} \wedge \mathrm{q}$ & $\mathrm{p} \wedge \sim \mathrm{q}$ & $\sim \mathrm{p} \wedge \mathrm{q}$ & $\sim \mathrm{p} \wedge \sim \mathrm{q}$ \\
\hline 1 & 1 & 1 & 0 & 0 & 0 \\
1 & 0 & 0 & 1 & 0 & 0 \\
0 & 1 & 0 & 0 & 1 & 0 \\
0 & 0 & 0 & 0 & 0 & 1 \\
\hline
\end{tabular}

The above conjunctive sentences (conjunctions) are pairwise contrary, i.e. the Sheffer's disjunction of two sentences of each of the six pairs of the above

\footnotetext{
2 These connectives of natural language fulfill in sentences not only a logical, descriptive (communicative) role but also an expressive one (expressing psychical states of a speaker). Defining these connectives by means of well-known logical connectives of CPC, we omit of course their expressive functions in composed propositions.
} 
conjunctions is true (is a tautology), so the sentences can never both be true, but can both be false.

To each of the 6 pairs of contrary conjunctions from the following:

(i) $\mathrm{p} \wedge \mathrm{q}, \mathrm{p} \wedge \sim \mathrm{q}, \sim \mathrm{p} \wedge \mathrm{q}, \sim \mathrm{p} \wedge \sim \mathrm{q}$

there exists a pair of contradictory implications from the following pairwise subcontrary implications:

(ii) $\mathrm{p} \rightarrow \mathrm{q}, \mathrm{p} \rightarrow \sim \mathrm{q}, \sim \mathrm{p} \rightarrow \mathrm{q}, \sim \mathrm{p} \rightarrow \sim \mathrm{q}$

so the sentences that can both be true, but cannot both be false, i.e. the disjunction of which is true. The implications (ii), of course, are true in three cases depending on the truth value of sentences $\mathrm{p}$ and $\mathrm{q}$.

Each pair of (ii), together with the suitable pair of contrary conjunctions of (i), creates one of the 6 squares of opposition for complex sentences of classical logic. The squares are given below (see Squares 1-6).

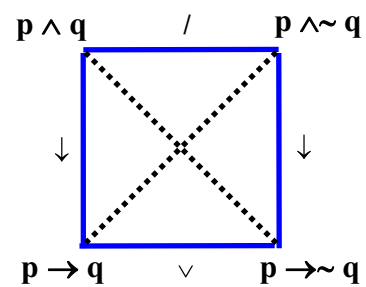

Square 1.

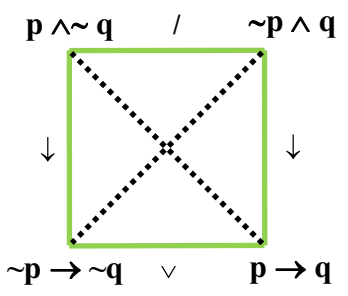

Square 4.

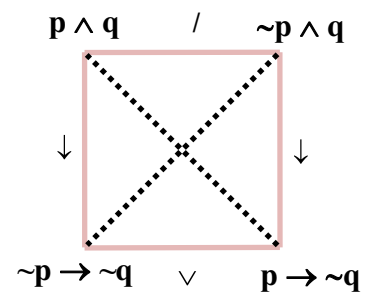

Square 2.

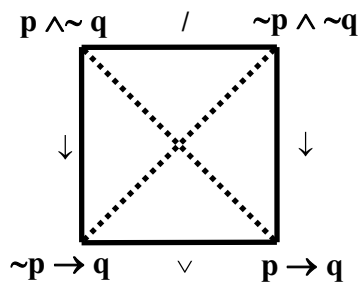

Square 5.

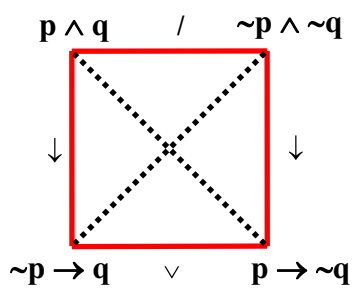

Square 3.

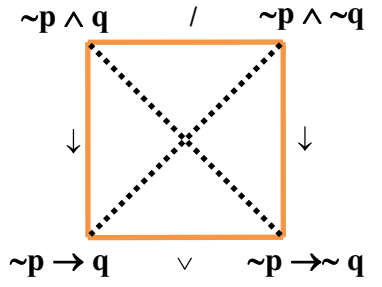

Square 6.

To each of the 6 pairs of contrary conjunctions from the following:

(i) $\mathrm{p} \wedge \mathrm{q}, \mathrm{p} \wedge \sim \mathrm{q}, \sim \mathrm{p} \wedge \mathrm{q}, \sim \mathrm{p} \wedge \sim \mathrm{q}$

there exists a pair of contradictory Sheffer's disjunctions (denial alternatives) from the following pairwise subcontrary Sheffer's disjunctions, i.e. the disjunction of which is true:

(iii) $\mathrm{p} / \mathrm{q}, \mathrm{p} / \sim \mathrm{q}, \sim \mathrm{p} / \mathrm{q}, \sim \mathrm{p} / \sim \mathrm{q}$. 
Each pair of (iii) together with the suitable pair of conjunctions of (i), creates one of the six squares of opposition for complex sentences of classical logic (see Squares $\left.1^{\prime}-6^{\prime}\right) .^{3}$

To each of the six pairs of contrary conjunctions from (i) there exists also a pair of contradictory disjunctions from the following pairwise subcontrary disjunctions, i.e. the disjunction of which is true:

(iv) $\mathrm{p} \vee \mathrm{q}, \mathrm{p} \vee \sim \mathrm{q}, \sim \mathrm{p} \vee \mathrm{q}, \sim \mathrm{p} \vee \sim \mathrm{q}$

Each pair of (iv), juxtaposed with the suitable pair of conjunctions from (i), creates also one of the six the squares of opposition for complex classical sentences (see Squares $\left.1^{\prime \prime}-6^{\prime \prime}\right){ }^{4}$

Squares $1^{\prime}-6^{\prime}$ and $1^{\prime \prime}-6^{\prime \prime}$ are given below:

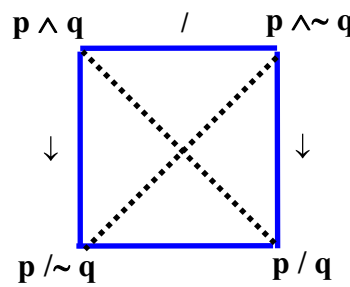

Square 1'.

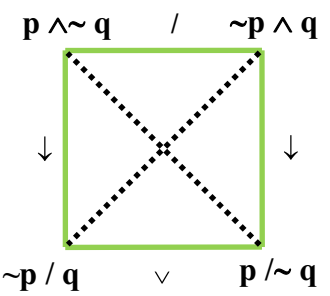

Square 4'.

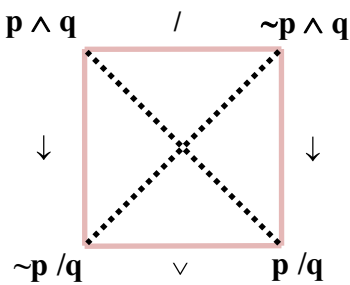

Square 2'.

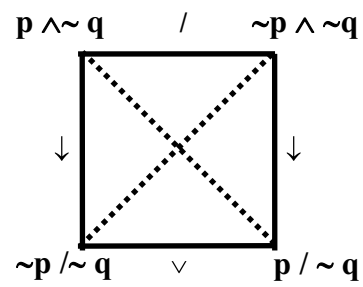

Square $5^{\prime}$.

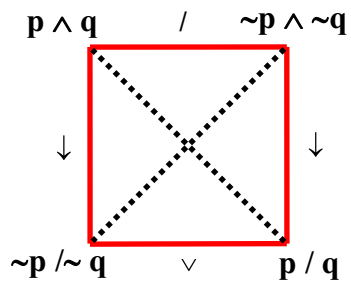

Square 3'.

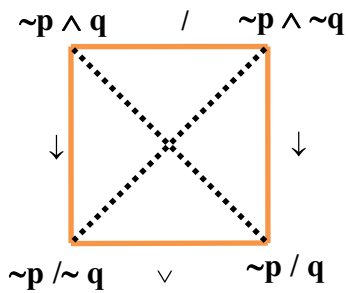

Square 6'.

\footnotetext{
${ }^{3}$ Squares $1^{\prime}-6^{\prime}$ are formed with the suitable Squares $1-6$ by replacing in them implications by equivalent Sheffer's disjunctions.

${ }^{4}$ Squares $1^{\prime \prime}-6{ }^{\prime \prime}$, are formed with the suitable Squares 1-6 (resp. Squares $1^{\prime}-6^{\prime}$ ) by replacing in them implications (resp. Sheffer's disjunctions) by equivalent disjunctions.
} 


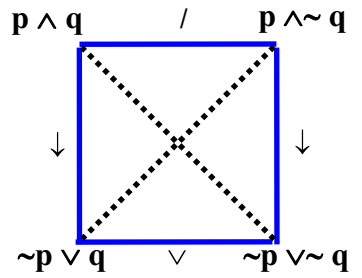

Square 1",

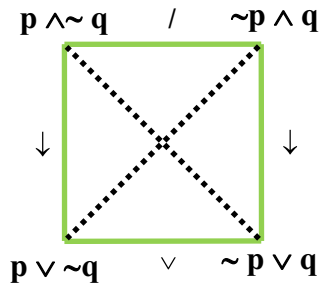

Square 4'.

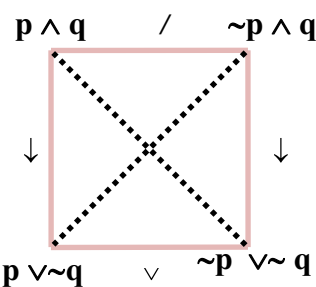

Square 2".

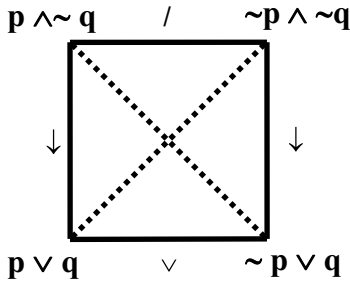

Square 5'.

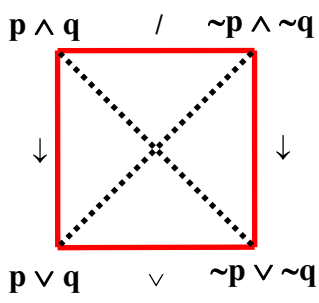

Square 3'.

As it turns out, at least one of them, Square $3^{\prime \prime}$ :

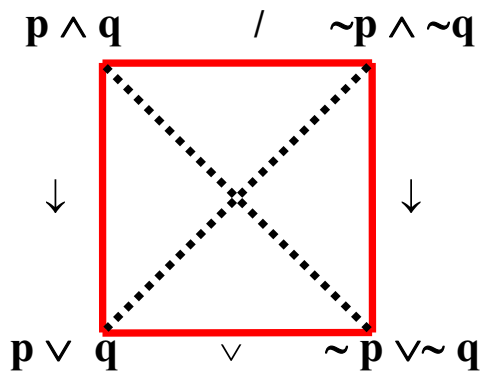

was known much earlier (see $[4,7,11-13,19,21],{ }^{5}[8]$.

So, if we have, for example, $\mathrm{p} \approx$ John is a scientist, $\mathrm{q} \approx$ John is a priest, then their conjunction: John is a scientist and John is a priest is contrary to their binegation: neither John is a scientist nor John is a priest; their disjunction: John is a scientist or John is a priest is subcontrary to the disjunction of their negations; their conjunction is contradictory to the disjunction of their negations and their binegation is contradictory to their disjunction;

\footnotetext{
${ }^{5}$ A fragment of the book of Żarnecka Biały (pp. 65-66) devoted to the theory of opposition and to Petrus Hispanus (Pope John XXII, in 13th century) suggests that the square was known to him. However, as Wojciech Suchoń informed me, in Petrus Hispanus's Summulae logicales there is no reference to the square of opposition for complex sentences, although it contains some material that allows for such digressions (cf. my abstract in [18]).
} 
from their conjunction follows their disjunction and from their binegation follows disjunction of their negations.

We may illustrate each of the six squares of opposition: Squares 1-6 (resp. Squares $1^{\prime}-6^{\prime}$ or Squares $1^{\prime \prime}-6^{\prime \prime}$ ), and properly corresponding to them six rectangles of opposition, in one of the octagons of opposition: Octagon 1 (resp. Octagon 2 or Octagon 3). For Squares $1^{\prime \prime}-6^{\prime \prime}$ we have Octagon 3 in which, for clarity, we omitted the doted, diagonal lines indicating contradictory sentences.

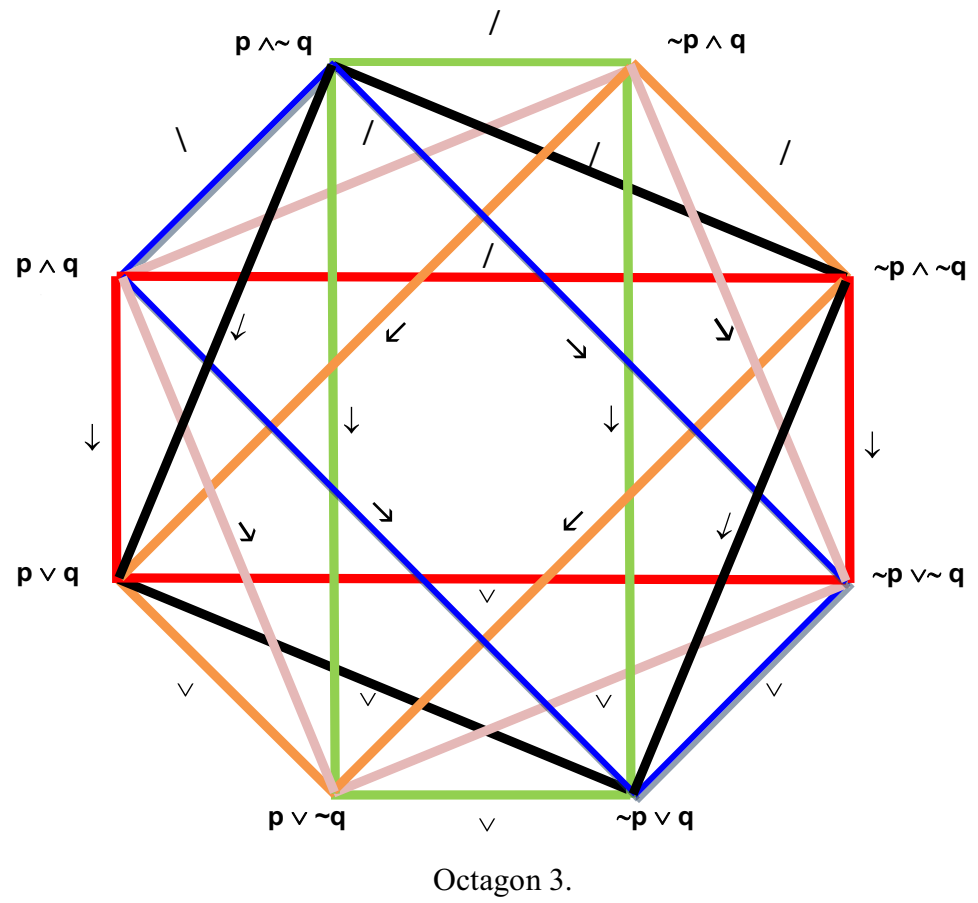

This octagon is another representation of the so called logical cube (well known in literature) which constitutes the central part of bigger 3D representations which unite all 14/16 formulas of CPC. It occurs in $[8,9,13,14]$.

For Squares $1-6$ and $1^{\prime}-6^{\prime}$ we obtain Octagon 1 and Octagon 2 in which disjunctions of (iv) are either replaced by equivalent implications from (ii) or by equivalent Sheffer's disjunctions from (iii), respectively.

Among the 16 connectives of the set F16 of the all binary connectives of classical logic we may find six which form true sentences in two cases and one which forms a true sentence in four cases. We will consider them in the next sections. 


\section{Connectives: ... even if...; even if. ..,...;.. if and only if. ..; either...or...}

3.1. The six binary classical sentence-forming connectives that form true sentences in two cases are defined as follows:

$$
\begin{aligned}
& \mathrm{p} \text { even if } \mathrm{q}(\mathrm{p}<\mathrm{q})={ }_{\mathrm{df}} \mathrm{q} \vee \sim \mathrm{q} \rightarrow \mathrm{p} \equiv \mathrm{p} ; \sim \mathrm{p} \text { even if } \sim \mathrm{q}(\sim \mathrm{p}<\mid \sim \mathrm{q}) \\
& =_{\mathrm{df}} \mathrm{q} \vee \sim \mathrm{q} \rightarrow \sim \mathrm{p} \equiv \sim \mathrm{p} ; \\
& \text { even if } \mathrm{p}, \mathrm{q}(\mathrm{p} \mid>\mathrm{q})={ }_{\mathrm{df}} \mathrm{p} \vee \sim \mathrm{p} \rightarrow \mathrm{q} \equiv \mathrm{q} ; \quad \text { even if } \sim \mathrm{p}, \sim \mathrm{q}(\sim \mathrm{p} \mid>\sim \mathrm{q}) \\
& =_{\mathrm{df}} \mathrm{p} \vee \sim \mathrm{p} \rightarrow \sim \mathrm{q} \equiv \sim \mathrm{q} ; \\
& \mathrm{p} \text { if and only if } \mathrm{q}(\mathrm{p} \equiv \mathrm{q})=_{\mathrm{df}}(\mathrm{p} \wedge \mathrm{q}) \vee(\sim \mathrm{p} \wedge \sim \mathrm{q}) ; \quad \text { either } \mathrm{p} \text { or } \mathrm{q}(\mathrm{p} \perp \\
& \mathrm{q})={ }_{\mathrm{df}} \sim(\mathrm{p} \equiv \mathrm{q}) .
\end{aligned}
$$

We see that sentences in the same line on the right side and on the left side are contradictory.

The connective $\perp(\vee \vee, \underline{V})$ is well known as the strong or exclusive disjunction connective. The sentence: even if $p, q\left(\left.p\right|^{>} q\right)$ can be read: even if $p$ then $\mathrm{q}$, and the sentence: even if $\sim \mathrm{p}, \sim \mathrm{q}\left(\left.\sim \mathrm{p}\right|^{>} \sim \mathrm{q}\right)$ can be read: even if not $\mathrm{p}$ then not $\mathrm{q}$.

The truth-value table for the connectives $<||>$,, $\equiv$ and $\perp$ is the following (see Table 2) ${ }^{6}$ :

TABLE 2. The truth-value table for connectives: $\langle||>,, \equiv, \perp$

\begin{tabular}{llllllllll}
\hline $\mathrm{p}$ & $\mathrm{q}$ & $\mathrm{p}^{<} \mid \mathrm{q}$ & $\sim \mathrm{p}^{<} \sim \sim \mathrm{q}$ & $\left.\mathrm{p}\right|^{>} \mathrm{q}$ & $\left.\sim \mathrm{p}\right|^{>} \sim \mathrm{q}$ & $\mathrm{p} \equiv \mathrm{q}$ & $\mathrm{p} \perp \mathrm{q}$ \\
\hline 1 & 1 & 1 & 0 & 1 & 0 & 1 & 0 \\
1 & 0 & 1 & 0 & 0 & 1 & 0 & 1 \\
0 & 1 & 0 & 1 & 1 & 0 & 0 & 1 \\
0 & 0 & 0 & 1 & 0 & 1 & 1 & 0 \\
\hline
\end{tabular}

In every two successive columns with composed propositions we have two contradictory sentences. For each pair of contradictory sentences in Table 2 we can build four squares of opposition and two hexagons of opposition corresponding to them.

The idea of constructing hexagons built from the squares of oppositions (rectangles of opposition corresponding to them) differs from the main idea of Blanché's hexagon (1966) presented clearly by Béziau [1] and based on putting together two triangles of opposition: the triangle of contrariety and the triangle of subcontrariety.

6 The sentence $\sim \mathrm{p}<\mid \sim \mathrm{q}$ can be replaced by the sentence $\sim \mathrm{p}<\mid$ q and the sentence $\left.\sim \mathrm{p}\right|^{>} \sim \mathrm{q}$ - by the sentence $\left.\mathrm{p}\right|^{>} \sim \mathrm{q}$. 
3.2. For $\mathrm{p}^{<} \mid \mathrm{q}$ and $\sim \mathrm{p}^{<} \mid \sim \mathrm{q}(\sim \mathrm{p}<\mid \mathrm{q})$ we have Squares 7 and 8 and Hexagon 1 (in which Square $6^{\prime \prime}$ is also illustrated) and Squares $7^{\prime}$ and $8^{\prime}$ and Hexagon $1^{\prime}$ (in which Square $1^{\prime \prime}$ is illustrated).

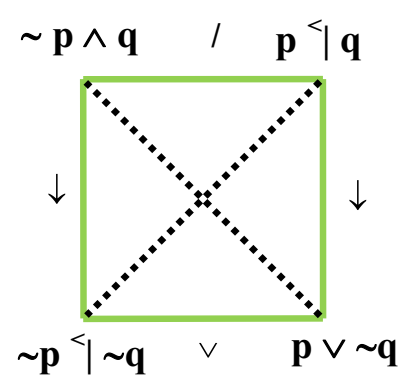

Square 7.

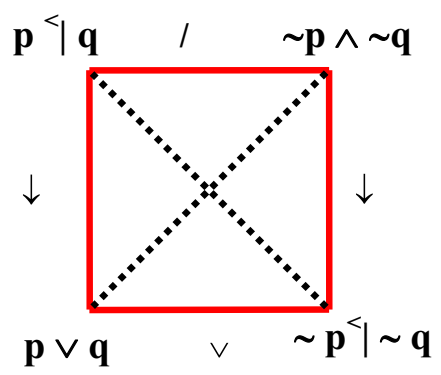

Square 8 .

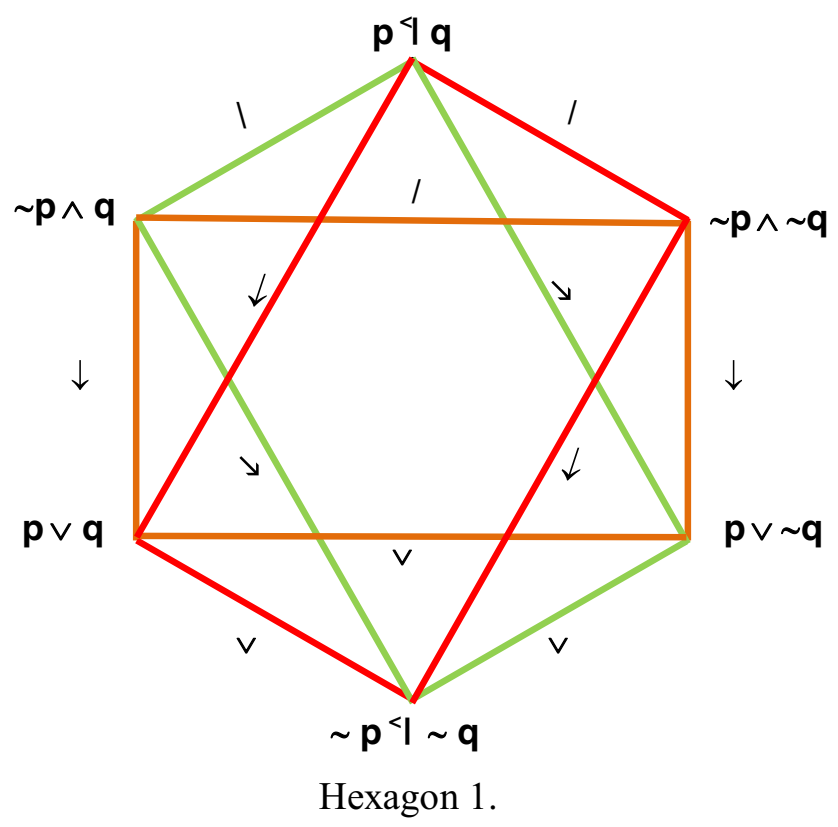

We obtain Hexagon 1 by composition of Squares 7 and 8 . The crucial difference between this Hexagon and the classical one from [4] is that two triangles of contrariety and subcontrariety do not overlap, and that all entailment relations are systematically pointed downwards, all contraries relations are shown in its upper triangle and all subcontriaries relations on its bottom triangle. Hexagon 1 is a simple graphical variant of the standard Blanche hexagon which is obtained by flipping the vertical diagonal of contradiction upside down. ${ }^{7}$

\footnotetext{
7 I owe this remark to the reviewer of my paper.
} 
Hexagon $1^{\prime}$ is obtained here by composition of the above mentioned Squares $7^{\prime}$ and $8^{\prime}$ :

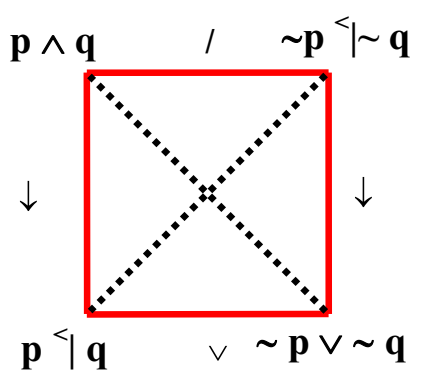

Square 7'.

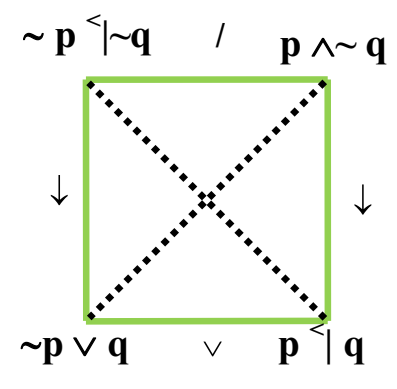

Square 8'.

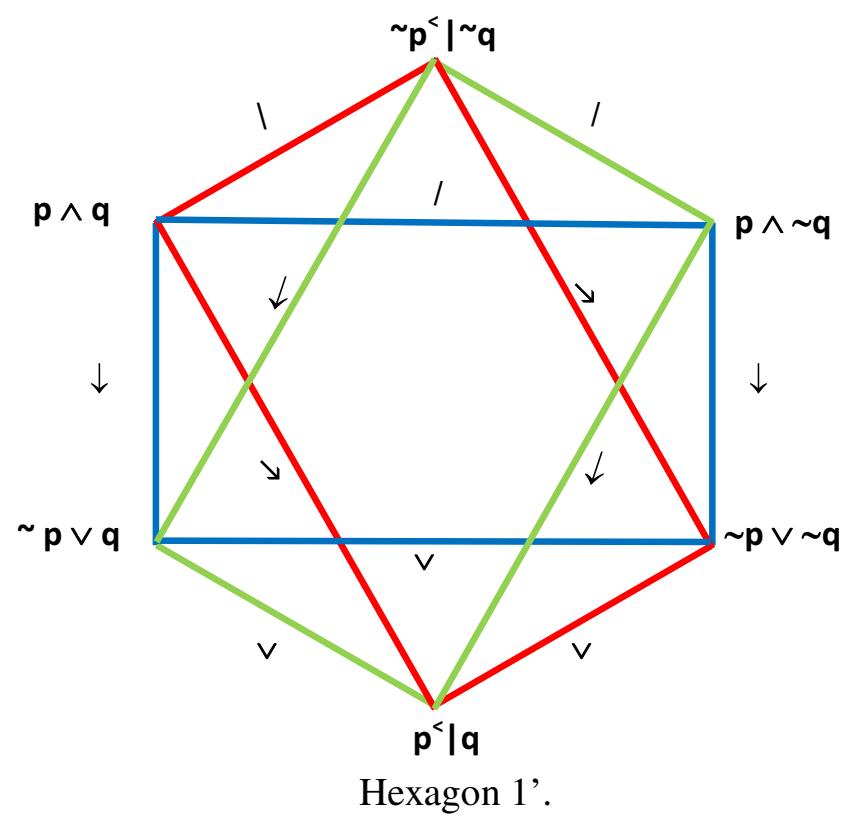

Let us return to the first square of the series of squares. Let us consider an example of using Square 7 with contradictory sentences $\mathrm{p}<\mid \mathrm{q}$ and $\sim$ p $<1 \sim$ q.

Let $\mathrm{p}$ be a sentence: He goes for a walk, and q a sentence: It rains. Then

- the sentence $\mathrm{p}<\mid \mathrm{q}$ : He goes for a walk even if it rains-

is contrary to

the sentence $\sim \mathrm{p} \wedge \mathrm{q}$ : He does not go for a walk because ( $\underline{\text { and })}$ it rains;

- the sentence $\mathrm{p}<\mid \mathrm{q}:$ He goes for a walk even if it rains is contradictory to

the sentence $\sim \mathrm{p}{ }^{<} \sim \mathrm{q}$ : He does not go for a walk even if it does not rain; 
- $\quad$ the sentence $\sim \mathrm{p} \wedge \mathrm{q}:$ He $\underline{\text { does not go for a walk because }}$ (and) it rains is contradictory to

the sentence $\mathrm{p} \vee \sim \mathrm{q}$ : He goes for a walk or it does not rain;

- the sentence $\mathrm{p}<\mid \mathrm{q}$ : He goes for a walk even if it rains

implies the sentence $\mathrm{p} \vee \sim \mathrm{q}$ : He goes for a walk or it does not rain;

- the sentence $\sim \mathrm{p} \wedge \mathrm{q}:$ He $\underline{\text { does not }}$ go for a walk because $(\underline{\text { and }})$ it rains

implies the sentence $\sim \mathrm{p}<\mid \sim \mathrm{q}$ : He does not go for a walk even if it does not rain;

- the sentence $\mathrm{p} \vee \sim \mathrm{q}$ : He goes for a walk or it does not rain and the sentence $\sim \mathrm{p}<\mid \sim \mathrm{q}$ : He does not go for a walk even if it does not rain are subcontrary.

3.3. For contradictory sentences $\left.\mathrm{p}\right|^{>} \mathrm{q}$ and $\left.\sim \mathrm{p}\right|^{>} \sim \mathrm{q}\left(\left.\mathrm{p}\right|^{>} \sim \mathrm{q}\right)$ we have Squares 9 and 10 and Hexagon 2, and also Squares $9^{\prime}$ and $10^{\prime}$ and Hexagon $2^{\prime}$.

Below we have Squares 9 and 10:

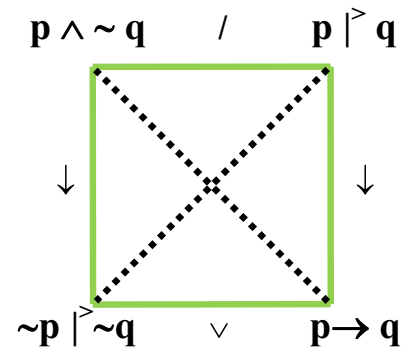

Square 9.

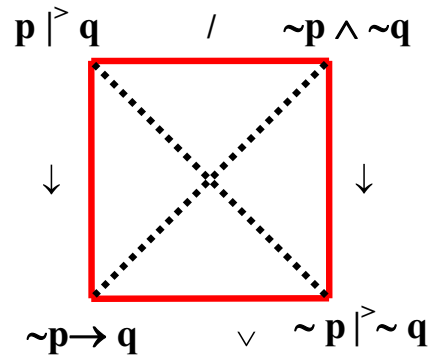

Square 10.

Let us consider an example of using Square 9 with contradictory sentences $\left.\mathrm{p}\right|^{>} \mathrm{q}$ and $\left.\sim \mathrm{p}\right|^{>} \sim \mathrm{q}$. Let us recall that the sentence: $\mathrm{p}$ unless $\mathrm{q}={ }_{\mathrm{df}} \sim(\mathrm{p} \rightarrow$ $\mathrm{q}) \equiv \mathrm{p} \wedge \sim \mathrm{q}$. And let $\mathrm{p}$ be a sentence: The reviewer rejected this paper, and q a sentence: It will be published.

Then

- the sentence $\left.\mathrm{p}\right|^{>} \mathrm{q}$ : Even if the reviewer rejected this paper, it will be published

is contrary to

the sentence $\mathrm{p} \wedge \sim \mathrm{q}(\mathrm{p}$ unless $\mathrm{q}, \sim(\mathrm{p} \rightarrow \mathrm{q}))$ : It is not truth that if the reviewer rejected this paper it will be published; 
- the sentence $\left.\mathrm{p}\right|^{>} \mathrm{q}:$ Even if the reviewer rejected this paper, it will be published,

is contradictory to

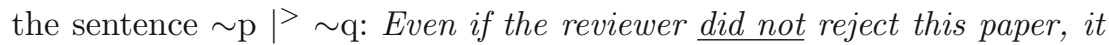
will not be published;

- the sentence $\mathrm{p} \wedge \sim \mathrm{q}$ : The reviewer rejected this paper $\underline{\text { unless }}$ it will be published

\section{is contradictory to}

the sentence $\mathrm{p} \rightarrow \mathrm{q}:$ If the reviewer rejected this paper then it will be published;

- the sentence $\left.\mathrm{p}\right|^{>} \mathrm{q}$ : Even if the reviewer rejected this paper, it will be published

implies the sentence $\mathrm{p} \rightarrow \mathrm{q}:$ If the reviewer rejected this paper then it will be published;

- the sentence $\mathrm{p} \wedge \sim \mathrm{q}$ : The reviewer rejected this paper unless it will be published

implies the sentence $\left.\sim \mathrm{p}\right|^{>} \sim \mathrm{q}:$ Even if the reviewer $\underline{\text { did not }}$ reject this paper, it will not be published;

- the sentence $\mathrm{p} \rightarrow \mathrm{q}:$ If the reviewer rejected this paper then it will be published, and the sentence $\left.\sim \mathrm{p}\right|^{>} \sim \mathrm{q}$ : Even if the reviewer did not reject this paper, it will not be published, are subcontrary.

Below we present Squares $9^{\prime}$ and $10^{\prime}$ :

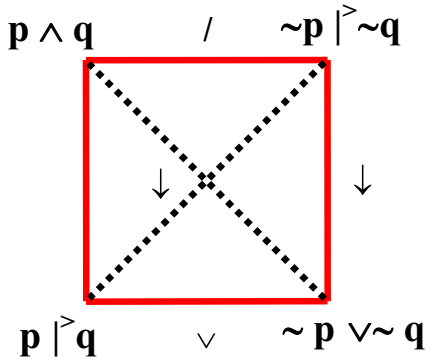

Square 9'.

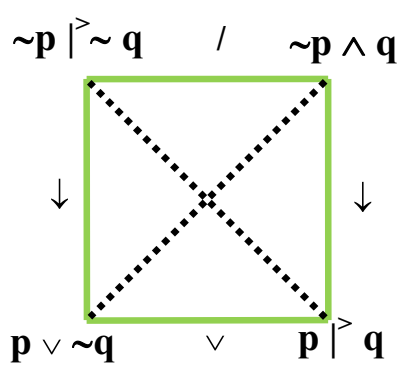

Square 10 . 
By composition of Squares 9 and 10 (resp. Squares $9^{\prime}$ and $10^{\prime}$ ) we obtain Hexagon 2 (resp. Hexagon $2^{\prime}$ ):

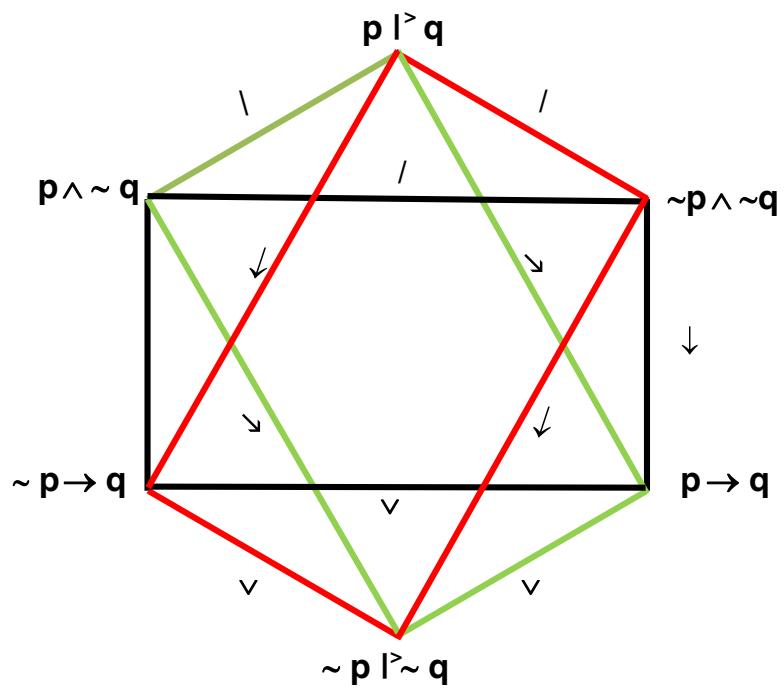

Hexagon 2.

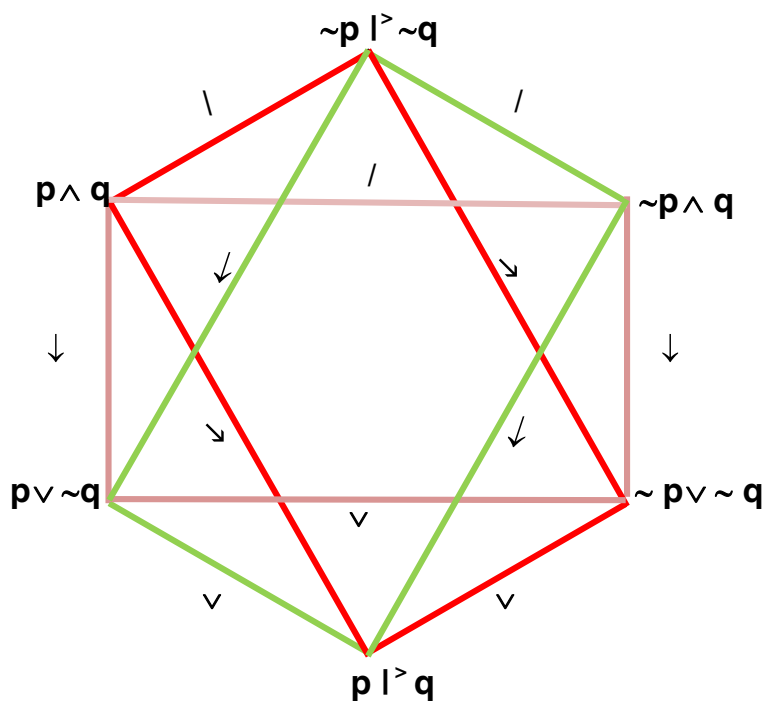

Hexagon 2'.

In Hexagon 2 and Square 5 is also illustrated, while in Hexagon $2^{\prime}$ and Square $2^{\prime \prime}$ is presented. 
3.4. For contradictory sentences $\mathrm{p} \equiv \mathrm{q}$ and $\mathrm{p} \perp \mathrm{q}$ we have Squares 11 and 12 and Hexagon 3 (in which Square 4 is also illustrated) and also Squares 11' and $12^{\prime}$ and Hexagon $3^{\prime}$ (in which Square 3 is also presented).

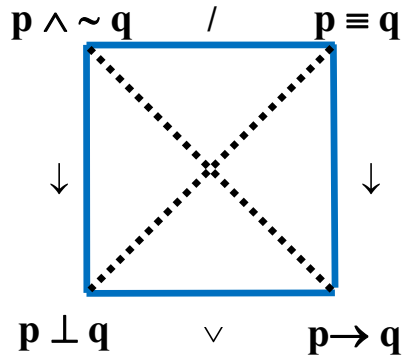

Square 11.

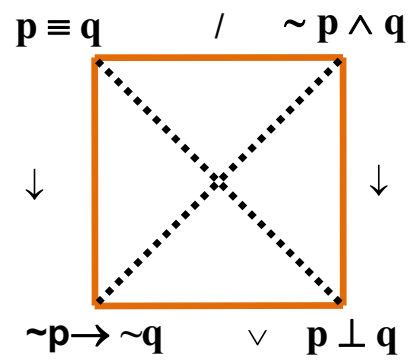

Square 12.

The composition of Squares 11 and 12 is Hexagon 3:

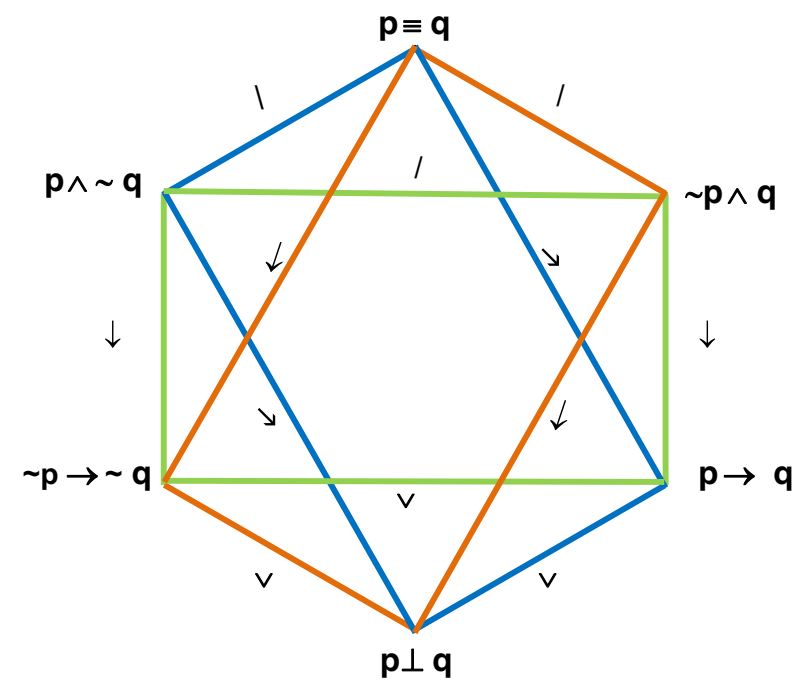

Hexagon 3.

Let us consider an example using the relationships in Square 12. Let us assume that the sentence $\mathrm{p} \approx$ This paper will be published, $\mathrm{q} \approx$ This paper has good reviews. Let us also recall that the sentence: not $\mathrm{p}$ because $\mathrm{q}={ }_{\mathrm{df}} \sim(\mathrm{q} \rightarrow$ p) $\equiv \sim \mathrm{p} \wedge \mathrm{q}$. So

- the sentence $\mathrm{p} \equiv \mathrm{q}$ : This paper will be published if and only if this paper has good reviews is contrary to

the sentence $\sim \mathrm{p} \wedge \mathrm{q}:$ This paper will not be published though it has good reviews;

- the sentence $\mathrm{p} \equiv \mathrm{q}$ : This paper will be published if and only if this paper has good reviews is contradictory to

the sentence $\mathrm{p} \perp \mathrm{q}$ : Either this paper will be published or it has good reviews; 
- the sentence $\mathrm{p} \equiv \mathrm{q}$ : This paper will be published if and only if this paper has good reviews implies the sentence $\mathrm{q} \rightarrow \mathrm{p}:$ If this paper has good reviews then it will be published;

- $\quad$ the sentence $\sim \mathrm{p} \wedge \mathrm{q}$ : This paper will not be published though it has good reviews

\section{is contradictory to}

the sentence $\mathrm{q} \rightarrow \mathrm{p}$ : If this paper has good reviews then it will be published;

- $\quad$ the sentence $\sim \mathrm{p} \wedge \mathrm{q}$ : This paper will not be published though it has good reviews

- $\quad$ implies the sentence $\mathrm{p} \perp \mathrm{q}$ : Either this paper will be published or it has good reviews.

Squares $11^{\prime}$ and $12^{\prime}$ and Hexagon $3^{\prime}$ are given below.

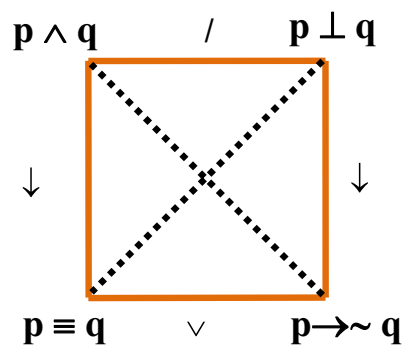

Square 11'.

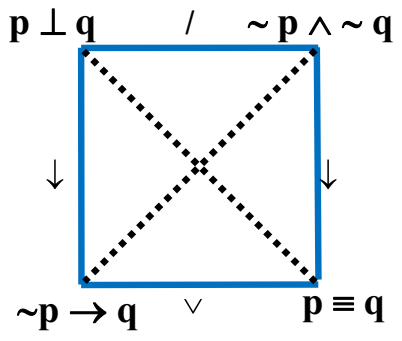

Square 12'.

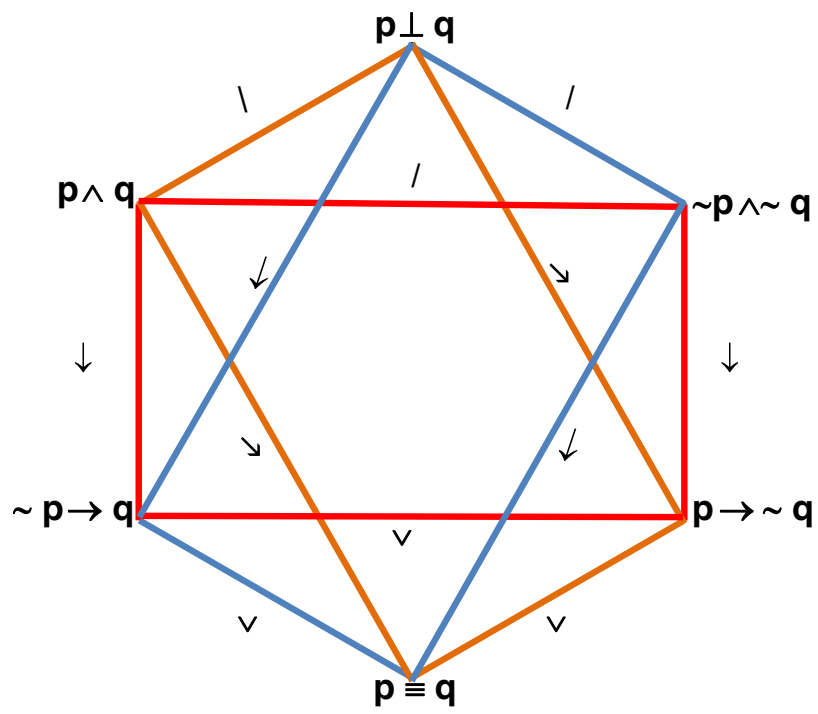

Hexagon 3'.

3.5. The relationships illustrated by means of Hexagons $1-3$ can be shown by means of three octahedrons of opposition, respectively. The relationships 
illustrated by means of Hexagons $1^{\prime}-3^{\prime}$ can be also shown by means of three other octahedrons of opposition, respectively.

In the book by [20] the relationships illustrated in Hexagon 3 are illustrated below by means of the so-called Ośmiościan logiczny (Logical Octahedron). Żarnecka-Biały used in the octahedron $\alpha, \beta$ for $\mathrm{p}$, q; dotted lines-for indicating contradictory sentences; the sign \&-for the conjunction connective $\wedge$, and the symbol $\vee$ with the dot on top-for the strong disjunctive connective $\perp$. It should, however, be observed that instead of $\alpha \rightarrow \beta$ there should be $\beta \rightarrow \alpha$, and reversely.

The figure depicted as Octahedron 3 is the Żarnecka-Biały's original Logical Octahedron picture given in our presented above changed symbolism.

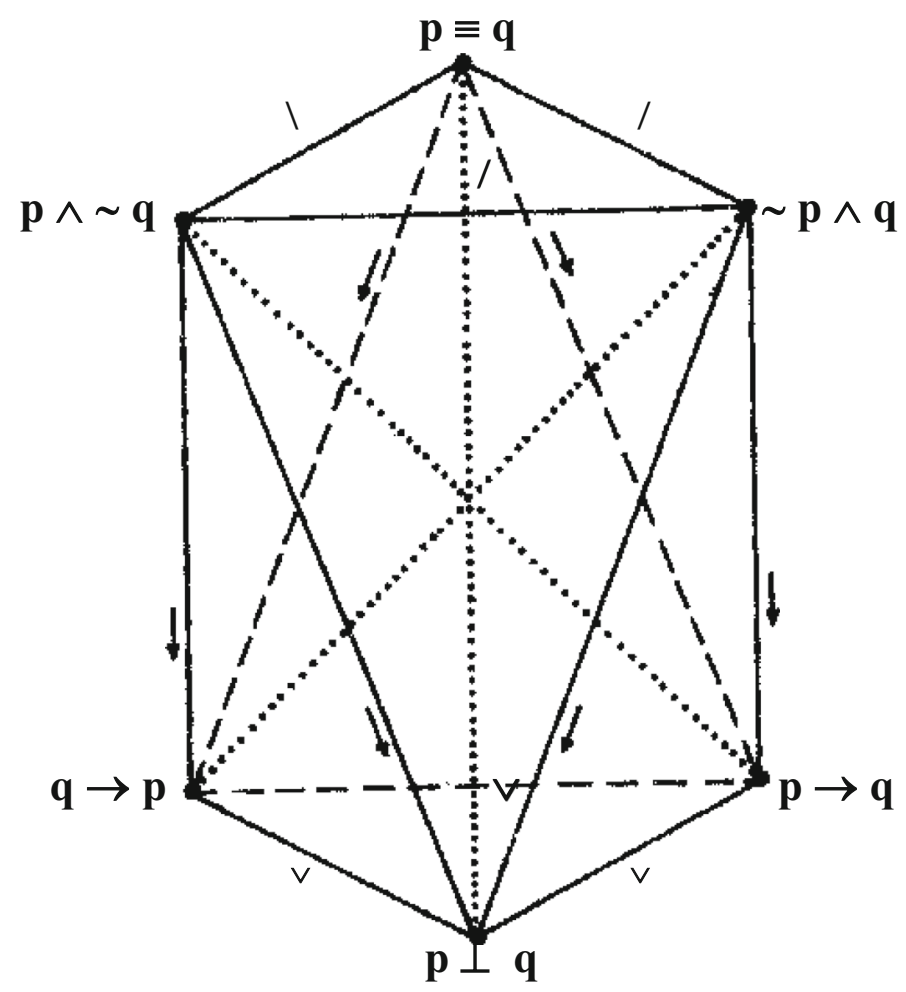

Octahedron 3.

In Octahedron 3 we have eight triangular faces: $(1) \wedge(\mathrm{q} \rightarrow \mathrm{p}, \mathrm{p} \perp \mathrm{q}, \mathrm{p}$ $\rightarrow \mathrm{q}),(2) \wedge(\mathrm{p} \perp \mathrm{q}, \mathrm{p} \rightarrow \mathrm{q}, \sim \mathrm{p} \wedge \mathrm{q}),(3) \wedge(\mathrm{p} \wedge \sim \mathrm{q}, \mathrm{q} \rightarrow \mathrm{p}, \mathrm{p} \perp \mathrm{q}),(4) \wedge(\mathrm{p}$ $\wedge \sim \mathrm{q}, \mathrm{p} \perp \mathrm{q}, \sim \mathrm{p} \wedge \mathrm{q}),(5) \wedge(\mathrm{p} \wedge \sim \mathrm{q}, \mathrm{p} \equiv \mathrm{q}, \sim \mathrm{p} \wedge \mathrm{q}),(6) \wedge(\mathrm{q} \rightarrow \mathrm{p}, \mathrm{p} \wedge \sim \mathrm{q}$, $\mathrm{p} \equiv \mathrm{q}),(7) \wedge(\mathrm{q} \rightarrow \mathrm{p}, \mathrm{p} \equiv \mathrm{q}, \mathrm{p} \rightarrow \mathrm{q}),(8) \wedge(\mathrm{p} \equiv \mathrm{q}, \sim \mathrm{p} \wedge \mathrm{q}, \mathrm{p} \rightarrow \mathrm{q})$

We can easily get other octahedrons of opposition: Octahedron 1 and Octahedron 2, corresponding to Hexagon 1 and Hexagon 2, respectively, and Octahedrons $1^{\prime}, 2^{\prime}, 3^{\prime}$ corresponding to Hexagons $1^{\prime}, 2^{\prime}$ and $3^{\prime}$, respectively. 


\section{6. "Degenerate" Squares}

On the basis of composed formulas in Table 2 it is possible to generate three more squares, which are "degenerate" in that they only preserve the diagonals of contradiction, but lose all the other relations (contrariety, subcontrariety and subalternation):
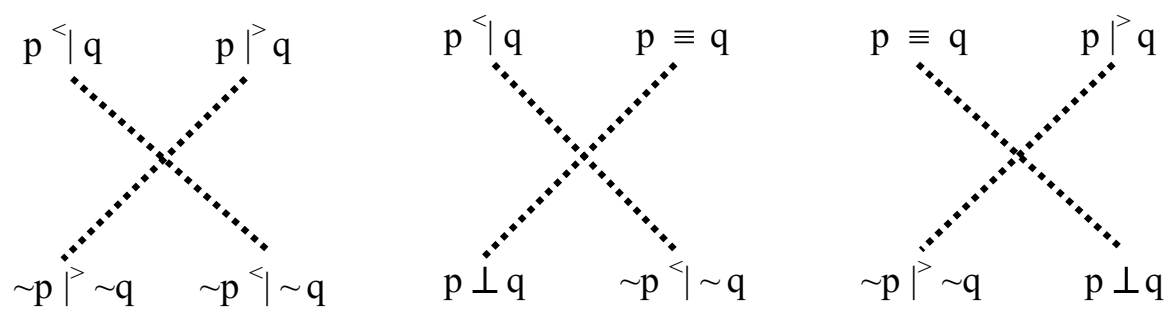

This type of squares ${ }^{8}$ is also called "unconnectedness square" (see [15]) and is called by Béziau the "X of oppositions" (2012).

\section{Binary Connectives: verum and falsum}

So far we have considered:

Four binary connectives which form true classical sentences in one case (see Table 1; Sect. 2),

Six binary connectives which form true sentences in two cases (see Table 2; Sect. 3).

Four implicational connectives which form sentences given in (ii)

[resp. equivalent Sheffer's disjunctive connectives which form sentences given in (iii) or equivalent disjunctive connectives forming propositions given in (iv)] that form true sentences in three cases.

All these 14 connectives of the set F16 of all the binary connectives of CPC were taken into consideration while forming some sentences which help to establish appropriate relationships in the squares of opposition given above.

So it remains to consider what relationships are between all of the 14 distinguished connectives of the set F16 and the connectives: p $\mathrm{T}$ q]

It is always truth independently of $\mathrm{p}$ and $\mathrm{q}$ [symbolically: $\mathrm{T}(\mathrm{p}, \mathrm{q})$ or

and p F q]

It is always falsity independently of $\mathrm{p}$ and $\mathrm{q}$ [symbolically: $\mathrm{F}(\mathrm{p}, \mathrm{q})$ or

called here binary verum and binary falsum, respectively. They are defined in Table 3 .

\footnotetext{
8 The squares were indicated by the reviewer of this paper.
} 
TABLE 3. The truth-value table for connectives verum $\mathrm{T}$ and falsum $\mathrm{F}$

\begin{tabular}{llll}
\hline $\mathrm{p}$ & $\mathrm{q}$ & $\mathrm{p}$ T q & p F q \\
\hline 1 & 1 & 1 & 0 \\
1 & 0 & 1 & 0 \\
0 & 1 & 1 & 0 \\
0 & 0 & 1 & 0 \\
\hline
\end{tabular}

For these contradictory connectives verum $\mathrm{T}$ and falsum $\mathrm{F}$, together with each connective $c \neq \mathrm{T}$ and $c \neq \mathrm{F}$ of the set $\mathrm{F} 16$, we may build 14 squares of opposition in the following form:

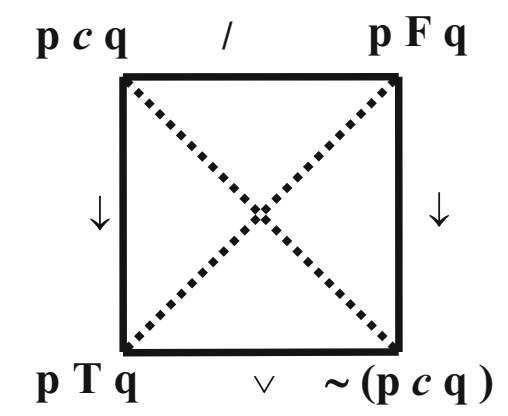

Squares for verum and falsum.

\section{Square for Unary Connectives}

The last squares correspond to the known square of opposition for unary connectives: assertion a, falsum $f$, verum $v$ and negation $\sim$, which has the following form:

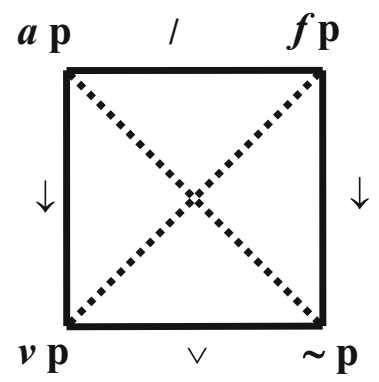

Square for unary connectives 


\section{Conclusion}

In Sects. 2-5 we were able to consider all the squares of opposition relationships for all sentences built from connectives of classical logic (CPC): 16 binary and 4 unary. $^{9}$

In Sect. 2 we showed that on the basis of four composed sentences in Table 1 we can built six basic squares of opposition with numbers 1-6 (so called "balanced" squares in literature). In Sect. 3 we showed that on the basis of Table 2 we can built 12 squares of opposition, so call "unbalanced" squares, with numbers $7-12$ and $7^{\prime}-12^{\prime}$ (and 6 hexagons with numbers $1-3$ and $\left.1^{\prime}-3^{\prime}\right)$. Moreover, it is also possible to generate three more "degenerate" squares (see Sect. 3.6).

Generally, we can say that on the basis of Tables 1 and 2, CPC contains 21 squares of opposition.

In Sect. 4 we considered additionally 14 squares of opposition for the binary connectives: verum and falsum. In Sect. 5 we also present one square of opposition for unary connectives of CPC.

As we could see, replacing categorical sentences in the traditional square of opposition with the suitable formulas of the classical propositional calculus (CPC) is a fully justified generalization of the idea of the logical square of opposition. This idea was known earlier ever since Blanché and Sauriol in the literature but based on other methods presented squares of oppositions for CPC.

\section{Acknowledgements}

I would like to thank an unknown reviewer and Jean-Yves Beziau for their useful remarks and suggestions, which helped to improve and complete this paper with the necessary literature references and graphic figures which were omitted in the previous version of the paper.

Open Access. This article is distributed under the terms of the Creative Commons Attribution 4.0 International License (http://creativecommons.org/licenses/ by/4.0/), which permits unrestricted use, distribution, and reproduction in any medium, provided you give appropriate credit to the original author(s) and the source, provide a link to the Creative Commons license, and indicate if changes were made.

\section{References}

[1] Béziau, J.-Y.: The power of hexagon. Log. Univers. 6, 1-2 (2012). (Special Issue: Hexagon of Opposition. Ed. J.-Y. Béziau, pp. 1-43)

[2] Béziau, J.-Y.: Synopsis of Robert Blanché, 'Sur le systme des connecteurs interpropositionnels'. In: Hallward, P. (ed.) Concept and Form: The Cahiers pour 1'Analyse and Contemporary French Thought. Centre for Research in Modern

\footnotetext{
${ }^{9}$ A different ("tetrahedronal") approach to the description of the relations among the 16 binary connectives is presented in the paper of Dubois and Prade [6, Section 2.3]. Another (tetrahexahedronal) solution is presented by Moretti [10, Figs. 15, 19]. The standard tetrahexahedron is presented earlier in [13] as well as [8].
} 
European Philosophy (CRMEP) and Kingston University (2011). http://cahiers. kingston.ac.uk/synopses/syn10.7.html

[3] Blanché, R.: Sur la structuration du tableau des connectifs interpropositionnels binaires. J. Symb. Log. 22, 1, 17-18 (1957)

[4] Blanché, R.: Structures intellectualles. Essai sur l'organisation systématique des Concepts. Vrin, Paris (1966)

[5] Blanché, R.: Sur le systeme des Connecteurs interpropositionnels. Casher pour l'Anal. 10, 131-149 (1969)

[6] Dubois, D., Prade, H.: From Blanchés hexagonal organization of concept to formal concept analysis and possibility theory. Log. Univers. 6, 1-2 (2012). (Special Issue: Hexagon of Opposition, Ed. J.-Y. Béziau, pp. 149-169)

[7] Gottschalk, W.H.: The theory of quaternality. J. Symb. Log. 18, 193-193 (1953)

[8] Luzeaux, D., Sallantin, J., Dartnell, C.: Logical extensions of Aristotle's square. Log. Univers. 2(1), 167-187 (2008)

[9] Moretti, A.: The geometry of opposition and the opposition of logic to it. In: Savardi, U. (ed.) The Perception and Cognition of Contraries. McGraw-Hill, Milano (2009)

[10] Moretti, A.: Way the logical hexagon? Log. Univers. 6, 1-2 (2012). (Special Issue: Hexagon of Opposition. Ed. J.-Y. Béziau, pp. 69-107)

[11] Piaget, J.: Traité de logique. Essai de syllogistique opératoire. Armand Coin, Paris (1949)

[12] Pogorzelski, W.A.: Elementarny Słownik Logiki Formalnej (Elemantary vocabulary of formal logic). In: Editorial Office of Warsaw University-Białystok Branch, Białystok, pp. 245-247 (1989)

[13] Sauriol, P.: Remarques sur la Théorie de l'hexagone logique de Blanché. Dialogue 7, 374-390 (1968)

[14] Smessaert, H.: On the 3D visualization of logical relations. Log. Univers. 3(2), 303-332 (2009)

[15] Smessaert, H., Demey, L.: Logical geometries and information in the square of opposition. JoLLI 23(4), 527-565 (2014)

[16] Wybraniec-Skardowska, U.: Foundations for the formalization of metamathematics and axiomatizations of consequence theories. In: Adamowicz, Z. et al. (eds.) Provinces of Logic Determined, Essays in the Memory of Alfred Tarski. Annales of Pure and Applied Logic, vol.127, Part IV, pp. 234-266. Elsevier Sciences, London (2004)

[17] Wybraniec-Skardowska, U., Waldmajer J.: On pairs of dual consequence operations. Log. Univers. 5(2), 177-203 (2011)

[18] Wybraniec-Skardowska, U.: Handbook of the World Congress on the Square of Opposition IV. In: Bézieu, J.-Y., Gan-Krzywoszyńska, K. (eds.) Pontifical Lateran University, Vatican, pp. 149-150 (2014)

[19] Zellweger, S.: Untapped potential in Peirce's iconic notation for sixteen binary connectives. In: Houser, N., Roberts, D. (eds.) Studies in the Logic of Charles Peirce, pp. 334-386. Indiana University Press, Bloomington (1997)

[20] Żarnecka Biały, E.: Historia logiki dawniejszej (History of formerly logic). In: Dialogikon Series. Jagiellonian University Press, Kraków (1995)

[21] Żarnecka Biały, E.: Mała logika (Small Logic), 3rd edn. Jagiellonian University Press, Kraków (1999) 
Urszula Wybraniec-Skardowska

Department of Philosophy

Cardinal Stefan Wyszyński University in Warsaw

01-938 Warsaw

Poland

e-mail: skardowska@gmail.com

Received: May 29, 2014.

Accepted: March 13, 2016. 